\title{
Dietary-induced changes in the fatty acid profile of rat pancreatic membranes are associated with modifications in acinar cell function and signalling
}

\author{
Maria D. Yago, Ricardo J. Diaz, Rolando Ramirez, Maria A. Martinez, Mariano Mañas* \\ and Emilio Martinez-Victoria \\ Institute of Nutrition and Food Technology, Department of Physiology, University of Granada, C/ Ramon y Cajal 4, \\ 18071 Granada, Spain
}

(Received 6 May 2003 - Revised 27 September 2003 - Accepted 8 October 2003)

\begin{abstract}
The effects of dietary lipids on the fatty acid composition of rat pancreatic membranes and acinar cell function were investigated. Weaning rats were fed for 8 weeks on one of two diets which contained $100 \mathrm{~g}$ virgin olive oil (OO) or sunflowerseed oil (SO)/kg. Pancreatic plasma membranes were isolated and fatty acids determined. Amylase secretion and cytosolic concentrations of $\mathrm{Ca}^{2+}$ and $\mathrm{Mg}^{2+}$ were measured in pancreatic acini. Membrane fatty acids were profoundly affected by the diets; the rats fed OO had higher levels of $18: 1 n-9$ (42.86 (SEM $1.99) \%$ ) and total MUFA compared with the animals fed SO (25.37 (SEM 1.11) \%). Reciprocally, the SO diet resulted in greater levels of total and $n$-6 PUFA than the OO diet. The most striking effect was observed for $18: 2 n-6$ (SO 17.88 (SEM 1.32) \%; OO 4.45 (SEM $0 \cdot 60$ ) \%), although the levels of $20: 4 n-6$ were also different. The proportion of total saturated fatty acids was similar in both groups, and there was only a slight, not significant $(P=0 \cdot 098)$, effect on the unsaturation index. Compared with the OO group, acinar cells from the rats fed SO secreted more amylase at rest but less in response to cholecystokinin octapeptide, and this was paralleled by reduced $\mathrm{Ca}^{2+}$ responses to the secretagogue. The results confirm that rat pancreatic cell membranes are strongly influenced by the type of dietary fat consumed and this is accompanied by a modulation of the secretory activity of pancreatic acinar cells that involves, at least in part, $\mathrm{Ca}^{2+}$ signalling.
\end{abstract}

Dietary fat: Pancreatic acini: Membrane fatty acids: Cholecystokinin: Calcium signalling

It has been accepted for many years that the exocrine function of the pancreas is influenced by the type of dietary fat. The approach most frequently used to tackle this task has been the analysis of the enzyme content of the pancreas after feeding animals different dietary lipids (Sabb et al. 1986; Ricketts \& Brannon, 1994). The exact mechanisms by which this adaptive effect is brought about are not clear. Moreover, the enzyme content does not necessarily reflect the secretory activity of the organ. In previous studies, the in vivo pancreatic response after medium- or long-term intake of diets differing in the type of fat source has been examined (Ballesta et al. 1990; Yago et al. 1997a). These investigations indicated that pancreatic adaptation to dietary fat type is mediated, at least in part, by changes in the circulating levels of some gastrointestinal hormones (Serrano et al. 1997; Yago et al. 1997a,b). However, whether the secretory activity of pancreatic acinar cells is influenced directly by dietary fat alteration is unknown.

Dietary fats have been demonstrated to exert profound effects on membrane lipids in several tissues and cell types. In newly weaned rat pups, diets containing $20 \mathrm{~g}$ fat from different sources $/ 100 \mathrm{~g}$ affected the fatty acid composition of intestinal brush-border membranes after only $40 \mathrm{~h}$ of feeding (Wang et al. 1996). Also, the effects of olive-oil or sunflowerseed-oil diets $(10 \mathrm{~g}$ fat $/ 100 \mathrm{~g})$ were evident in plasma lipids (Giron et al. 1995) and liver microsomes (Giron et al. 1996) after $6 \mathrm{~d}$. The differences in fatty acid profiles were shown to be permanent, provided the animals were kept on the same diets (Wang et al. 1996). A time period of 6 weeks has been found to be enough to induce changes in adipocyte plasma membrane of weaning rats (Field et al. 1989). Also, some reports (Suarez et al. $1996 a, b)$ indicate that the rat heart, kidney, lung, erythrocytes and brain are also very responsive to modifications in dietary fatty acids during early postnatal life (4-6 weeks after weaning). Changes in membrane fatty acid composition may, in turn, influence cell function (Neelands \& Clandinin, 1983; Field et al. 1989; Clandinin et al. 1991; Vajreswari \& Narayanareddy, 1992; Wang et al. 1996; Quiles et al. 2001). This is not an unexpected finding, since there is growing evidence that fatty acids, in addition

\footnotetext{
Abbreviations: BSA, bovine serum albumin; CCK-8, cholecystokinin octapeptide; cPLA2, cytosolic Ca ${ }^{2+}$-dependent phospholipase $\mathrm{A}_{2}$; IP3, inositol trisphosphate; PLC, phospholipase C; PSS, physiological salt solution; SFA, saturated fatty acids; UI, unsaturation index.

* Corresponding author: Professor Mariano Mañas, fax + 34958 248326, email mariano@ugr.es
} 
to their role in determining membrane structure and fluidity, can participate in intracellular processes as diverse as signal transduction or the regulation of gene expression.

Thus, the aim of the present study was to investigate the effects of two dietary oils that differ markedly in their fatty acid profile (virgin olive oil and sunflowerseed oil) on the function of rat pancreatic acinar cells and if this could be related to the fatty acid composition of cell membranes. These oils were chosen because of their preferential use in the Granada geographical area. Furthermore, olive oil is a major component of the Mediterranean diet, and its role in human health is actively debated at present. In order to investigate the study's aim, diets containing either virgin olive oil or sunflowerseed oil were given to separate groups of rats for 8 weeks. Acinar cell function was assessed by determining basal and cholecystokinin octapeptide (CCK-8)-stimulated amylase release in suspensions of viable acini. The present study also examined the effect of these diets on the mobilisation of intracellular free $\mathrm{Ca}\left(\mathrm{Ca}^{2+}\right)$, a key mediator of CCK-8-evoked enzyme secretion, and on the changes in the cytosolic concentration of free $\mathrm{Mg}\left(\mathrm{Mg}^{2+}\right)$, an abundant cation that has been proposed to act as a $\mathrm{Ca}^{2+}$ antagonist.

\section{Methods}

\section{Materials}

Unless otherwise stated, all chemicals and solvents of the highest grade available were obtained from Sigma (St Louis, MO, USA) and Merck (Darmstadt, Germany).

\section{Animals and diets}

All experimental procedures were approved by the ethical committee of the Spanish Ministry of Science and Technology. The animals were handled according to the guidelines of the Spanish Society for Laboratory Animal Sciences and killed humanely. Seventy male weaning Wistar rats initially weighing $40-55 \mathrm{~g}$ (supplied by the animal farm at the University of Granada) were allocated to two groups (thirty-five each) so that the average weight per group was the same. The rats were fed over an 8-week period with two semi-purified, isoenergetic and isonitrogenous diets that were essentially AIN-93G diets (Reeves et al. 1993) except that the total fat content was increased from 70 to $100 \mathrm{~g} / \mathrm{kg}$ at the expense of carbohydrate. The composition of the diets $(\mathrm{g} / \mathrm{kg})$ was as follows: casein, 200; maize starch, 367.5; dyetrose, 132; sucrose, 100; cellulose, 50; fat, 100; L-cystine, 3; choline bitartrate, 2.5; AIN-93G mineral mixture, 35; AIN-93G vitamin mixture, 10 . The two diets differed only in the nature of the fat source; virgin olive oil or sunflowerseed oil. Commercial edible oils were obtained locally (Fedeoliva, S.A., Jaén, Spain and Koipesol ${ }^{\circledR}$; Koipe, S.A., Andújar, Juén, Spain). The fatty acid composition of the two oils (Table 1) was determined by GLC as described later for the membrane fractions. The experimental diets were prepared at the nutrition unit of the animal farm (University of Granada, Spain), packed in plastic bags, sealed, and sent to the laboratory, where they were
Table 1. Fatty acid composition of experimental fats (Mean values for five replicates)

\begin{tabular}{lcc}
\hline & $\begin{array}{c}\text { Olive oil } \\
(\mathrm{g} / 100 \mathrm{~g} \text { fatty acids })\end{array}$ & $\begin{array}{c}\text { Sunflowerseed oil } \\
(\mathrm{g} / 100 \mathrm{~g} \text { fatty acids })\end{array}$ \\
\hline $16: 0$ & 11.44 & 7.31 \\
$16: 1 n-7$ & 0.85 & 0.19 \\
$18: 0$ & 4.38 & 4.59 \\
$18: 1 n-9$ & 74.88 & 32.62 \\
$18: 2 n-6$ & 7.72 & $55 \cdot 17$ \\
$18: 3 n-3$ & 0.62 & 0.10 \\
Saturated fatty acids & 15.82 & 11.90 \\
Unsaturated fatty acids & 84.18 & $88 \cdot 10$ \\
MUFA & 75.84 & 32.83 \\
PUFA & 8.34 & 55.27 \\
\hline
\end{tabular}

stored at $4^{\circ} \mathrm{C}$ in the dark. During the 8-week adaptation period to the diets, the animals were housed individually in a temperature-controlled room $\left(22 \pm 1^{\circ} \mathrm{C}\right)$, kept on a $12 \mathrm{~h}$ light-dark cycle and given free access to water and food. Food intake was determined daily in a subset of rats from both groups ( $n 8$ each). Body weight was recorded weekly. Feeding diets varying in the fat source did not affect daily food intake or body-weight gain during the 8-week adaptation period; accordingly, there was no difference between the groups in the weight of pancreases (data not shown). All rats in the present study were killed by severance of the vertebral column after an overnight fast (food was always withheld from 20.00-20.30 and the time of killing was $09.00-09.30$ on the next morning).

\section{Isolation and analysis of cell membranes}

The rat pancreatic plasma membrane fractions were prepared from gland homogenates by differential and sucrose gradient centrifugation (Meldolesi et al. 1971). Next, the technique of Lepage \& Roy (1986) was used, a method that combines lipid extraction and fatty acid methylation in a one-step reaction. A GLC system, model HP 5890 series II (Hewlett Packard, Palo Alto, CA, USA), equipped with an automatic injector and a flame ionisation detector, was used to analyse fatty acids as methyl esters. Chromatography was performed using a $60 \mathrm{~m}$ long capillary column (32 mm internal diameter and $20 \mathrm{~mm}$ thickness) impregnated with Sp $2330^{\mathrm{TM}}$ FS (Supelco Inc., Bellefonte, CA, USA).

\section{Preparation of isolated rat pancreatic acini}

Acini were isolated according essentially to the modification (Jensen et al. 1982) of the procedure published previously (Peikin et al. 1978). Following killing, the pancreas was rapidly removed and trimmed free of fat and nodes in a physiological salt solution (PSS, $\mathrm{pH} 7.45$ ). The solution comprised (per litre): bovine serum albumin (BSA), $2 \mathrm{~g}$; soyabean trypsin inhibitor, $1 \mathrm{~g}$; glutamine, $0.3 \mathrm{~g}$; vitamin mixture (BME vitamins solution 100x; Sigma, St Louis, MO, USA), $10 \mathrm{ml}$; amino acid mixture (BME Amino Acids Solution 50x; Sigma), $25 \mathrm{ml}$. The PSS comprised (mM): $\mathrm{NaCl}, 120 ; \mathrm{KCl}, 7 \cdot 2$; sodium pyruvate, 6; sodium 
fumarate, 7.1; sodium glutamate, 6; glucose, 14; $\mathrm{KH}_{2} \mathrm{PO}_{4}$, $2 ; \mathrm{MgCl}_{2}, 1 \cdot 2 ; \mathrm{HEPES}, 24 ; \mathrm{CaCl}_{2}, 2$. Next, $2 \mathrm{ml}$ PSS containing $44 \mathrm{U}$ purified collagenase/ml (type CLSPA; Worthington Biochemical Corp., Lakewood, NJ, USA) were injected into the pancreas. The distended pancreas was incubated at $37^{\circ} \mathrm{C}$ for $30 \mathrm{~min}$ in a shaking water-bath, washed with fresh collagenase solution every $10 \mathrm{~min}$. This was followed by vigorous manual agitation. The dispersed acini were placed in cold PSS containing $40 \mathrm{~g} \mathrm{BSA} / 1$ and centrifuged $\left(50 \mathrm{~g}, 4 \mathrm{~min}, 4^{\circ} \mathrm{C}\right)$. The pellet was then re-suspended in PSS containing $2 \mathrm{~g}$ $\mathrm{BSA} / \mathrm{l}$. Following gentle pippeting, the digested material was filtered and centrifuged $\left(50 \mathrm{~g}, 4 \mathrm{~min}, 4^{\circ} \mathrm{C}\right)$. Cell viability was, at different times, monitored by trypan blue exclusion.

\section{Amylase release}

Amylase release was measured as described previously (Peikin et al. 1978; Jensen et al. 1982). In brief, acini were suspended in incubation medium (PSS containing $10 \mathrm{~g} \mathrm{BSA} / 1$ and $\left.0.5 \mathrm{~mm}-\mathrm{CaCl}_{2}\right)$. Samples $(500 \mu \mathrm{l})$ were then incubated at $37^{\circ} \mathrm{C}$ for $30 \mathrm{~min}$ with either $0 \cdot 1,1$ or $10 \mathrm{nM}-\mathrm{CCK}-8 \quad\left(\left[\mathrm{Tyr}\left(\mathrm{SO}_{3} \mathrm{H}\right)^{27}\right] \mathrm{CCK}\right.$ fragment 26-33 amide; Sigma) and this was followed by centrifugation at $350 \mathrm{~g}$ for $2 \mathrm{~min}\left(4^{\circ} \mathrm{C}\right)$. Acini exposed to the incubation medium alone served as unstimulated controls (basal release). Amylase activity in supernatant fractions was determined with the Phadebas reagent (Pharmacia \& Upjohn, Barcelona, Spain) and expressed as a percentage of total amylase content at the beginning that was released into the extracellular medium during the incubation.

\section{Measurement of intracellular free $\mathrm{Ca}^{2+}$ concentration}

Acini were suspended in sodium HEPES solution ( $\mathrm{pH}$ 7.40) containing (g/l): BSA, 2; soyabean trypsin inhibitor, 0.1. The HEPES solution contained (mM): $\mathrm{CaCl}_{2}, 1 ; \mathrm{NaCl}, 130 ; \mathrm{KCl}, 5$; HEPES, 20; $\mathrm{KH}_{2} \mathrm{PO}_{4}, 1 \cdot 2$; $\mathrm{MgSO}_{4}, 1$; glucose, 10. Cells were loaded with $2 \mu \mathrm{M}-$ fura-2 AM (Molecular Probes Europe BV, Leiden, The Netherlands) for $20 \mathrm{~min}$ at $37^{\circ} \mathrm{C}$ in a shaking water-bath, washed and re-suspended in the same solution without BSA or trypsin inhibitor. For quantification of fluorescence, samples of acinar suspension $(2 \mathrm{ml})$ were placed in a quartz cuvette in a Perkin-Elmer LS 50B spectrofluorimeter (Perkin-Elmer, Beaconfield, Bucks, UK) and continuously stirred at $37^{\circ} \mathrm{C}$. Fura-2-loaded cells were excited at 340 and $380 \mathrm{~nm}$, and emission was monitored at $510 \mathrm{~nm}$. After baseline measurement, CCK-8 was added into the cuvette to a final concentration of $0 \cdot 1,1$ or $10 \mathrm{~nm}$. At the end of each experiment, maximum and minimum fluorescence ratio values were obtained by the respective addition of digitonin (final concentration $80 \mu \mathrm{M})$ and ethylene-glycol-bis(a-aminoethyl)-N,N, $\mathrm{N}^{\prime}, \mathrm{N}^{\prime}-$ tetra-acetic acid- tri(hydroxymethyl)-aminomethane $\mathrm{pH}$ 8.7 (ethylene-glycol-bis (a-aminoethyl)-N,N, $\mathrm{N}^{\prime}, \mathrm{N}^{\prime}$-tetraacetic acid final concentration was $7 \mathrm{~mm}$ ). Values for intracellular free $\mathrm{Ca}^{2+}$ concentration were calculated according to Grynkiewicz et al. (1985).

\section{Measurement of intracellular free $\mathrm{Mg}^{2+}$ concentration}

The same protocol and technique described for intracellular free $\mathrm{Ca}^{2+}$ concentration measurement was used, but in this case cells were loaded with $2 \mu \mathrm{M}$-magfura-2 AM (Molecular Probes Europe BV, Leiden, The Netherlands) and fluorescence recorded from cell populations at excitation wavelengths of 335 and $370 \mathrm{~nm}$ and emission at $510 \mathrm{~nm}$. CCK-8 was assayed only at 1 and $10 \mathrm{~nm}$, since the response to lower concentrations is hardly detectable by this technique.

\section{Calculations and statistical analysis}

In order to calculate the integrated response in the $\mathrm{Ca}^{2+}$ experiments, the basal intracellular free $\mathrm{Ca}^{2+}$ concentration values before the addition of CCK- 8 were averaged to estimate the baseline and this was subtracted from each of the stimulation values. The numbers obtained in this way were then summed. The unsaturation index (UI) was calculated according to the formula: $\mathrm{UI}=(\Sigma$ (fatty acid content $\times$ number of double bonds))/total content of saturated fatty acids (SFA). The results presented in the text, tables and figures are means and standard errors of the mean. Before mean comparison, the normality of the distribution of values was checked using the KolmogorovSmirnov test. For variables with a normal distribution, the significance of mean differences among the dietary groups was assessed by the parametric Student's $t$ test. For variables lacking a normal distribution, the non-parametric Mann-Whitney U test was applied. In all cases, SPSS software was used (SPSS for Windows, version 11.0.1, 2001; SPSS Inc., Chicago, IL, USA). Only values of $P<0.05$ were considered significant.

\section{Results}

\section{Fatty acid profile of pancreatic cell membranes}

The fatty acid profile of pancreatic cell membranes (Table 2) was profoundly influenced by the dietary treatment. Membranes of the olive-oil-fed group were characterised by higher proportions of $18: 1 n-9$ $(P<0.001)$ and total MUFA $(P<0.001)$ as compared with the sunflowerseed-oil group. Reciprocally, feeding the polyunsaturated sunflowerseed-oil diet for 8 weeks resulted in enhanced levels of total PUFA $(P<0.001)$ in pancreatic membranes, particularly the $n-6$ series $(P<0.001)$, in comparison with olive-oil-fed animals. The elevated proportion of $n-6$ PUFA in the membranes of the sunflowerseed-oil group was due to the contribution of $18: 2 n-6$, the major fatty acid in sunflowerseed oil $(P<0.001 \quad v$. olive-oil group), but also of $20: 4 n-6$ $(P<0.05 v$. olive-oil group). The total amount of SFA was the same regardless of the diet. It is worth noting that, despite marked differences in the content of a number of individual fatty acids as well as in total MUFA and PUFA (Table 2), neither the SFA:unsaturated fatty acid value nor the UI were significantly different among the dietary groups. 
Table 2. Fatty acid profile of rat pancreatic cell membranes after the 8-week adaptation period to the experimental diets $(\mathrm{g} / 100 \mathrm{~g}$ total fatty acids) $\dagger$

(Mean values and standard errors of the mean)

\begin{tabular}{|c|c|c|c|c|}
\hline & \multicolumn{2}{|c|}{ Olive-oil group } & \multicolumn{2}{|c|}{$\begin{array}{l}\text { Sunflowerseed- } \\
\text { oil group }\end{array}$} \\
\hline & Mean & SEM & Mean & SEM \\
\hline $14: 0$ & $7 \cdot 76$ & 2.67 & 3.02 & $1 \cdot 15$ \\
\hline $16: 0$ & $25 \cdot 25$ & 0.49 & $27 \cdot 05$ & $1 \cdot 31$ \\
\hline $16: 1 n-7$ & $5 \cdot 15$ & 0.41 & $4 \cdot 21$ & 0.41 \\
\hline $18: 0$ & $6 \cdot 69^{* *}$ & 0.62 & $10 \cdot 25$ & 0.86 \\
\hline $18: 1 n-9$ & $42 \cdot 86^{\star \star \star}$ & 1.99 & $25 \cdot 37$ & $1 \cdot 11$ \\
\hline $18: 2 n-6$ & $4 \cdot 45^{\star \star \star}$ & 0.60 & $17 \cdot 88$ & $1 \cdot 32$ \\
\hline $18: 3 n-3$ & 0.39 & 0.04 & 0.31 & 0.08 \\
\hline $20: 4 n-6$ & $5 \cdot 54^{*}$ & 0.70 & 9.83 & 1.34 \\
\hline $20: 5 n-3$ & 0.629 & 0.061 & 0.455 & 0.134 \\
\hline $22: 6 n-3$ & 0.580 & 0.090 & 0.913 & 0.215 \\
\hline Saturated fatty acids & $39 \cdot 71$ & $2 \cdot 33$ & $40 \cdot 34$ & 2.02 \\
\hline MUFA & $48 \cdot 11^{\star \star \star}$ & 2.29 & $29 \cdot 72$ & 1.41 \\
\hline PUFA & $12 \cdot 17^{\star \star \star}$ & 1.41 & 29.94 & $2 \cdot 25$ \\
\hline$n-6$ PUFA & $10 \cdot 50^{\star \star \star}$ & $1 \cdot 28$ & $28 \cdot 15$ & $2 \cdot 18$ \\
\hline$n-3$ PUFA & 1.67 & 0.14 & 1.80 & 0.24 \\
\hline MUFA:PUFA & $4 \cdot 47^{\star \star \star}$ & 0.48 & $1 \cdot 12$ & 0.15 \\
\hline Unsaturation index & $2 \cdot 35$ & 0.22 & 3.04 & 0.30 \\
\hline
\end{tabular}

*Mean values were significantly different from those of the sunflowerseed-oil group: * $P<0.05,{ }^{* \star} P<0.005$, ${ }^{\star * *} P<0.001$ ( $n 12$ for both groups).

†For details of diets and procedure, see Table 1 and p. 228.

\section{Amylase release}

Basal values of amylase release were significantly higher $(P<0.001)$ in acini from the rats fed sunflowerseed oil $(12.2$ (SEM 0.5$) \% ; n 13)$ than in acini from the animals fed olive oil (5.9 (SEM 0.6) \%; $n$ 9). In both groups, net amylase release (above basal) in response to $0 \cdot 1-10 \mathrm{~nm}-$ CCK-8 showed the highest values at $0 \cdot 1 \mathrm{~nm}$ (Fig. 1) and decreased gradually with higher concentrations. However, at any particular concentration of the secretagogue, feeding the sunflowerseed-oil diet for 8 weeks was associated with a significant attenuation in CCK-8-stimulated net amylase release in rat pancreatic acini compared with the olive-oil diet (Fig. 1).

\section{Intracellular free $\mathrm{Ca}^{2+}$ concentration}

Basal values of intracellular free $\mathrm{Ca}^{2+}$ concentration (considering all the series) were 191.0 (SEM 9.4) nM ( $n$ 17) in acini from the olive-oil group and slightly lower in those from the sunflowerseed-oil group (175.9 (SEM 12.3) nM; $n$ 18). The time-course changes in intracellular free $\mathrm{Ca}^{2+}$ concentration evoked by CCK-8 (Fig. 2) showed the typical responses to $\mathrm{CCK}-8$ in acinar cell suspensions, i.e. a large transient increase followed by a slow decline towards a suprabasal level. Cells from both groups reacted with a very prompt rise in intracellular free $\mathrm{Ca}^{2+}$ concentration in response to 1 and $10 \mathrm{~nm}-\mathrm{CCK}-8$ (Fig. 2 (B) and (C)) whereas the time between the administration of the secretagogue until the intracellular free $\mathrm{Ca}^{2+}$ concentration maximum was reached increased when a concentration of $0 \cdot 1 \mathrm{nM}$ was used (Fig. 2 (A)). Data in Fig. 2 also indicate that $0 \cdot 1,1$ and $10 \mathrm{nM}-\mathrm{CCK}-8$ resulted in intracellular free $\mathrm{Ca}^{2+}$ concentration values that, not only at the peak response but also at many time points of the sustained

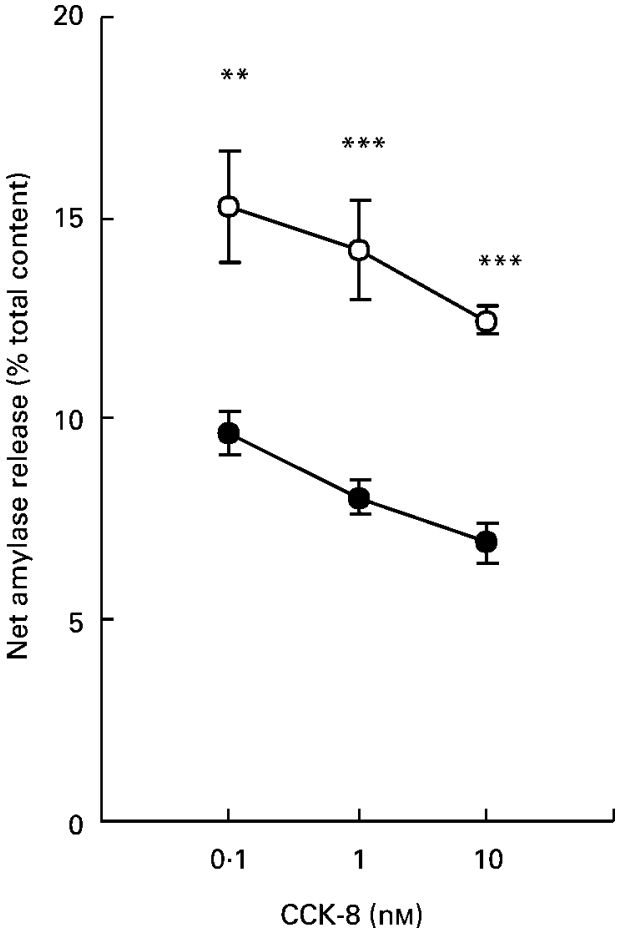

Fig. 1. Net amylase release (increase above basal) stimulated by cholecystokinin octapeptide (CCK-8) in pancreatic acini isolated from rats fed diets containing either virgin olive oil (-O-) or sunflowerseed oil (-๑) as the fat source. Amylase released during the incubation with the secretagogue $\left(30 \mathrm{~min}, 37^{\circ} \mathrm{C}\right)$ is expressed as a percentage of total initial content. Results are mean values of fifteen to thirty-seven separate experiments (in each experiment values were determined in duplicate). Standard errors of the mean are represented by vertical bars. Mean values were significantly different between the dietary groups: ${ }^{\star \star} P<0.005$, ${ }^{\star \star \star} P<0.001$.

phase, were significantly $(P<0 \cdot 05)$ higher in cells from the rats fed olive oil than in those isolated after sunflowerseedoil feeding. The differences were, however, less pronounced at $10 \mathrm{nM}-\mathrm{CCK}-8$ (Fig. 2 (C)). In fact, when the intracellular free $\mathrm{Ca}^{2+}$ concentration response is expressed as a peak increase relative to basal (Fig. 3 (A)) or as an integrated response (Fig. 3 (B)), the values attained with this concentration of the secretagogue were similar in both experimental groups.

\section{Intracellular free $\mathrm{Mg}^{2+}$ concentration}

Resting intracellular free $\mathrm{Mg}^{2+}$ concentration was comparable in both groups (Table 3). When CCK-8 was added, intracellular free $\mathrm{Mg}^{2+}$ concentration decreased gradually in cells from both dietary groups to reach a lower level 2-3 min later that persisted until the end of the experiment. This pattern of response was similar regardless of the antecedent diet and it is illustrated in Fig. 4, which reproduces an original trace of the changes evoked by $1 \mathrm{nM}$ in cells prepared from a sunflowerseed-oil-fed animal. The responses and corresponding decreases below basal after the stimulation of cells from both groups with 1 and $10 \mathrm{~nm}-\mathrm{CCK}-8$ are summarised in Table 3 . No significant differences were revealed between the experimental groups except for the decrease below basal evoked by $10 \mathrm{nM}-\mathrm{CCK}-8$. 

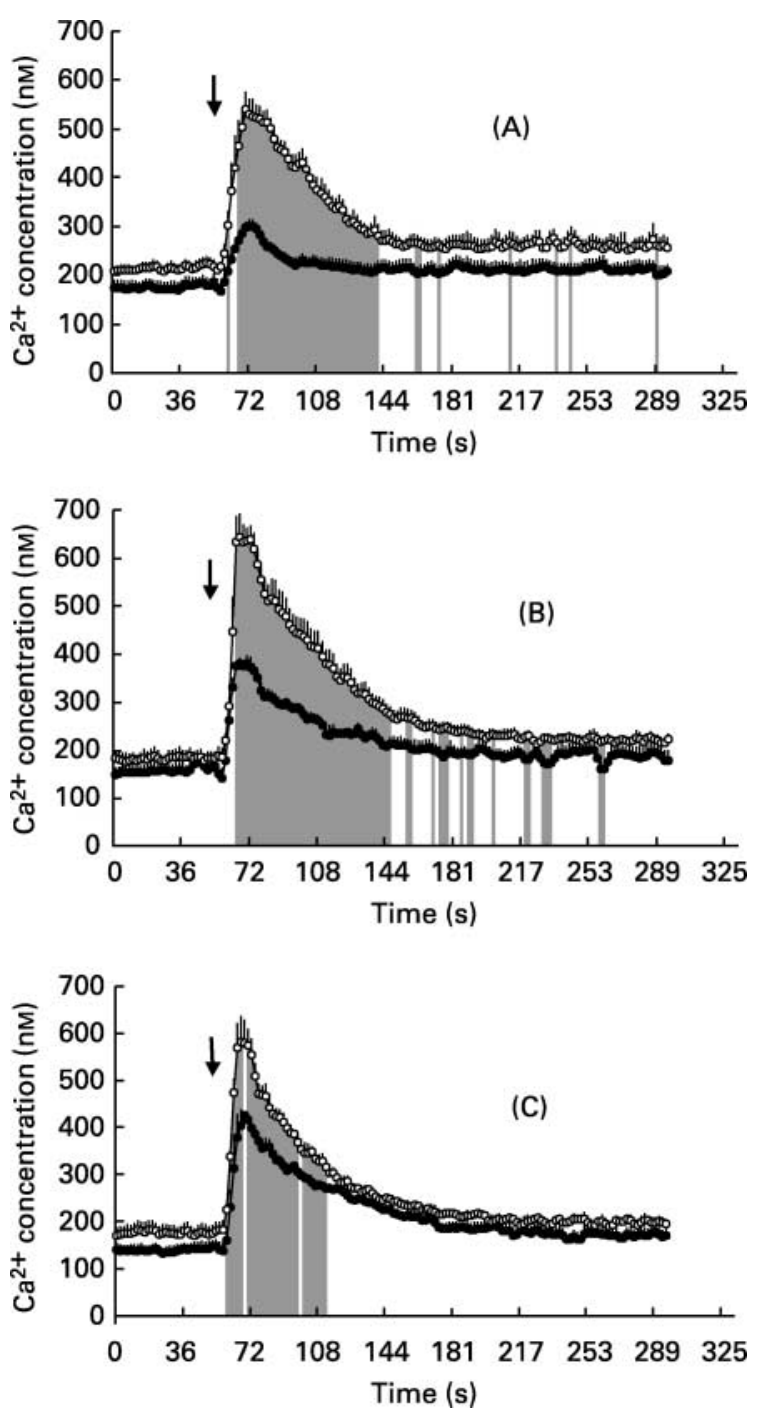

Fig. 2. Time-course changes in intracellular free $\mathrm{Ca}^{2+}$ concentration evoked by (A), $0.1 \mathrm{~nm}-$; (B), $1 \mathrm{~nm}-$; or (C), $10 \mathrm{~nm}$-cholecystokinin octapeptide (CCK-8) in suspensions of fura-2-loaded pancreatic acinar cells isolated from rats fed diets containing either virgin olive oil (-O-) or sunflowerseed oil (-๑-) as the fat source. Results are mean values of five to seven independent experiments. Standard errors of the mean are represented by vertical bars. ( $\downarrow)$, The point of addition of the secretagogue; $(\square)$, significant differences between the groups at individual time points $(P<0.05)$.

\section{Discussion}

Previous observations from the authors' research group in Spain (Quiles et al. 1999), along with those by other researchers (Neelands \& Clandinin, 1983; Clandinin et al. 1991; Vajreswari \& Narayanareddy, 1992), indicate that dietary fat composition influences the fatty acid profile of phospholipids in both cellular and subcellular membranes of different organs such as the heart, liver, muscle, etc. Reported changes reflect dietary variation but not always to the same extent, suggesting that this process does not depend only on fatty acid availability. Indeed, changes in the dietary fat consumed have been shown to affect the rate of phospholipid synthesis de novo, the redistribution of fatty acyl chains and the activity of desaturases and elongases (for a review, see Clandinin et al. 1991).
In addition, a clear influence of age, tissue and physiological state is to be considered. The present study confirms that the pancreas is very sensitive to dietary fat changes. Thus, after 8 weeks on the diets, pancreatic membranes in the olive-oil group had significantly higher levels of 18: $1 n-9$ and total MUFA, whereas a higher level of PUFA, particularly $n-6$ PUFA such as $18: 2 n-6$ and $20: 4 n-6$, was found in the sunflowerseed-oil group. To the authors' knowledge, only two groups have investigated the influence of the type of dietary fat on the lipid composition of the pancreas (Begin et al. 1990; Soriguer et al. 2000) and they also show an enrichment in the pancreas of those fatty acids most abundant in the fat ingested. The work by Soriguer et al. (2000) is especially interesting, given that their olive-oil and sunflowerseed-oil diets $(8 \mathrm{~g} /$ $100 \mathrm{~g}$ ) are very similar to those of the present study $(10 \mathrm{~g} / 100 \mathrm{~g})$. A discrepancy between their results and the present results concerns arachidonic acid (20:4n-6); while Soriguer et al. (2000) found comparable levels, the present results indicate a higher proportion in the animals fed sunflowerseed oil. Differences in the study design probably account for this. Thus, Soriguer et al. (2000) used adult rats that were fed with the experimental diets for 1 month only whereas the present study employed weaning rats and a longer feeding period (8 weeks). Early-life feeding experiences with diets of varying fatty acid composition may affect the ability of the intestine to adapt to an altered lipid intake in later life (Thomson et al. 1993). In addition, the minimal time to induce diet-induced changes in tissue lipids has been shown to be influenced by the characteristics of the antecedent diet (Berlin et al. 1998). Another aspect to take into account is that Soriguer et al. (2000) analysed the fatty acid composition of phospholipids extracted from whole-pancreas homogenates, but plasma membranes were used in the present study. Whether the difference in $20: 4 n-6$ proportion relates to this particularity remains to be elucidated.

In the present study, the proportion of total SFA was similar in the membranes of the two groups. In fact, except for 18:0 values, no further differences could be detected. This resistance of the SFA fraction to dietaryinduced alterations is a common feature in different tissues (Begin et al. 1990; Vajreswari \& Narayanareddy, 1992; Suarez et al. 1996b; Quiles et al. 1999; Soriguer et al. 2000). In addition, feeding diets rich in virgin olive oil or sunflowerseed oil did not alter significantly the total SFA:unsaturated fatty acid value or the UI. This suggests that membranes display a considerable degree of homeostasis with respect to these parameters (Vajreswari \& Narayanareddy, 1992), and that changes in the proportion of several major fatty acids are associated to some metabolic compensation in order to keep plasma membrane fluidity within a certain range of values.

The dose-response curve for CCK-8-induced amylase release in pancreatic acinar cells is typically bell-shaped, reaching a maximum at around $0.1 \mathrm{~nm}$ (Akiyama et al. 1998; Lajas et al. 1998). The lowest concentration of CCK-8 employed in the present study was $0.1 \mathrm{nM}$, so only data regarding the second phase of the curve are available. Still, the present results are consistent with those in the literature since, in the conditions used in the present 

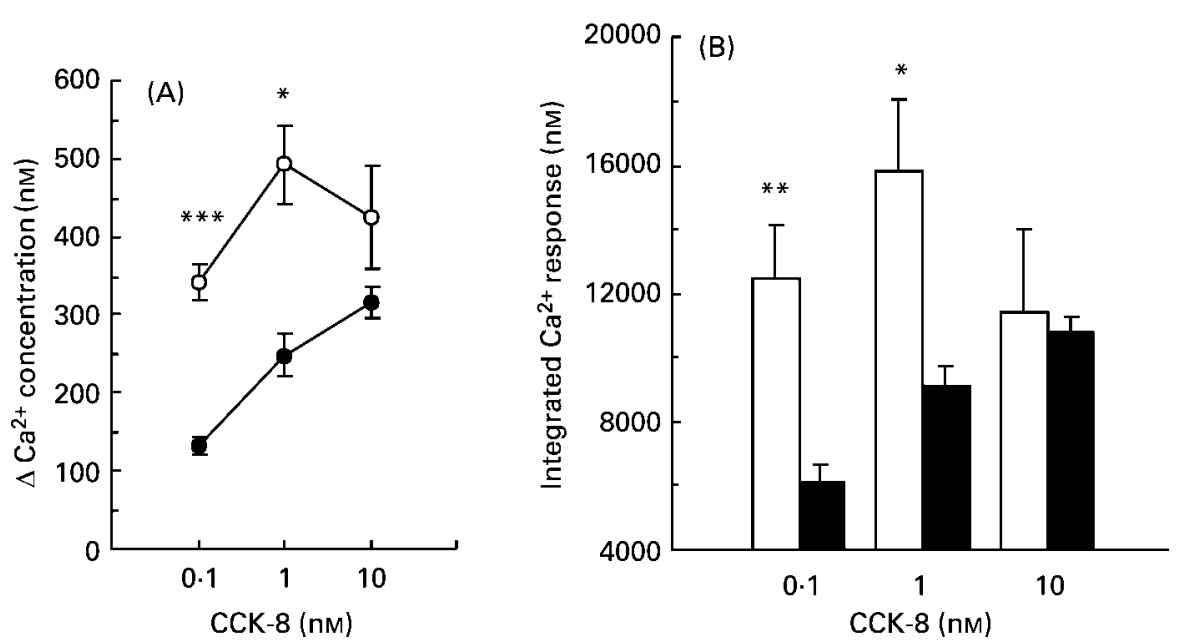

Fig. 3. Effect of graded concentrations of cholecystokinin octapeptide (CCK-8) on intracellular free $\mathrm{Ca}^{2+}$ concentration in suspensions of fura2-loaded pancreatic acinar cells isolated from rats fed diets containing either virgin olive oil (-O-, $\square)$ or sunflowerseed oil (- - -, $\mathbf{\square})$ as the fat source. (A), $\mathrm{Ca}^{2+}$ response expressed as increase above basal (difference between peak and basal value); (B), the integrated response calculated as described on p. 229. Results are mean values of five to seven independent experiments. Standard errors of the mean are represented by vertical bars. Mean values were significantly different between the dietary groups: ${ }^{\star} P<0.05$, ${ }^{\star *} P<0.005$, ${ }^{\star \star \star} P<0.001$.

study, the strongest secretory effect was observed at $0 \cdot 1 \mathrm{nM}-\mathrm{CCK}-8$ and a characteristic decrease occurred after the addition of higher concentrations of the secretagogue. This pattern was followed in cells from both the oliveoil and sunflowerseed-oil groups. Quantitatively, however, marked differences were revealed between the two dietary groups. Thus, values for basal (unstimulated) amylase release in acini from rats fed the olive-oil diet were similar to those reported by most authors (Akiyama et al. 1998; Lajas et al. 1998) whereas release in cells from the sunflowerseed-oil-fed rats was markedly higher. The reason for this effect is unknown. High basal values of amylase release have been found in acinar cells from pancreatitic rats and the authors related this finding to increased acinar intracellular free $\mathrm{Ca}^{2+}$ concentration (Bragado et al. 1996). Basal intracellular free $\mathrm{Ca}^{2+}$ concentration values were comparable in acini from the present study's two dietary groups, so they cannot account for the differences in amylase release in unstimulated conditions. The possibility exists that different membrane composition is modifying the permeability for amylase.
Were this true, it would be happening without a negative effect on membrane integrity, as indicated by the trypan blue exclusion test.

In contrast to the observations in basal conditions, net amylase secretion in response to all concentrations of CCK-8 was drastically reduced after sunflowerseed-oil feeding. This diminished secretory activity may be explained, without excluding other components of the secretory pathway, by the attenuation of CCK-8-evoked $\mathrm{Ca}^{2+}$ responses in the sunflowerseed-oil group. Moreover, the fact that not only the absolute value of the intracellular free $\mathrm{Ca}^{2+}$ concentration peak but also the peak increase over basal is lower in cells from the sunflowerseed-oilfed rats suggests a reduction in the filling state of CCK8 -releasable $\mathrm{Ca}^{2+}$ pools and/or a limitation in the production or effectiveness of the mediators that participate in the $\mathrm{Ca}^{2+}$ mobilisation pathways.

The differences in acinar secretory activity and intracellular free $\mathrm{Ca}^{2+}$ concentration mobilisation in the present study are most probably related to the dietary-induced changes in cell membrane composition. Dietary fats

Table 3. Intracellular free $\mathrm{Mg}^{2+}$ concentration in unstimulated conditions and effect of cholecystokinin octapeptide (CCK-8) in pancreatic acinar cells from rats fed diets containing either virgin olive oil or sunflowerseed oil $†$

(Mean values and standard errors of the mean)

\begin{tabular}{|c|c|c|c|c|c|c|c|c|c|c|c|c|}
\hline & \multicolumn{12}{|c|}{ Intracellular free $\mathrm{Mg}^{2+}$ concentration (mM) } \\
\hline & \multicolumn{6}{|c|}{ Olive-oil group ( $n 4-7$ ) } & \multicolumn{6}{|c|}{ Sunflowerseed-oil group ( $n$ 5-6) } \\
\hline & Mean & SEM & Mean & SEM & Mean & SEM & Mean & SEM & Mean & SEM & Mean & SEM \\
\hline 10 nм-CCK-8 & 1.017 & 0.120 & 0.826 & $0 \cdot 106$ & 0.156 & 0.022 & 0.939 & 0.113 & 0.674 & 0.081 & $0 \cdot 265^{\star}$ & 0.033 \\
\hline
\end{tabular}

*Decrease below basal mean value was significantly different, for the same concentration of CCK-8, from that for the olive-oil group $(P<0.05)$.

†For details of diets and procedures, see Table 1 and pp. 228-229.

$\ddagger$ Responses were calculated by averaging values once the new steady state had been reached.

$\S$ The decrease below basal represents the difference between the basal and the corresponding response. 


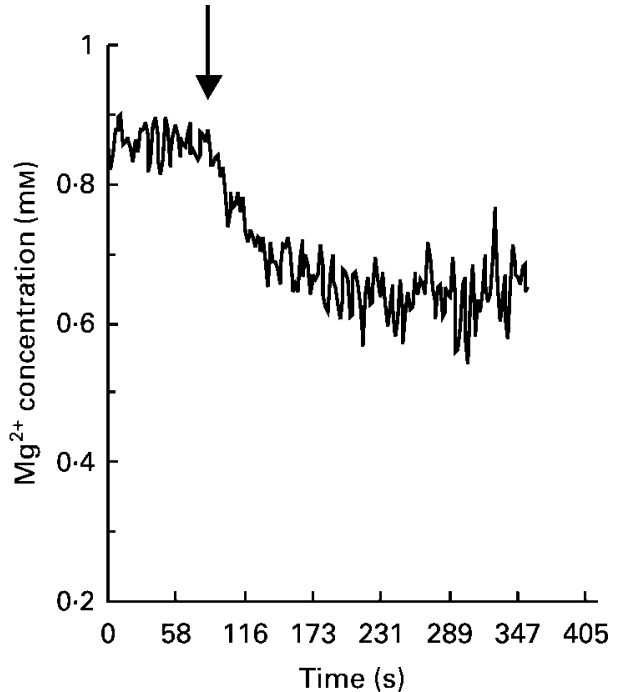

Fig. 4. Original trace-recording showing the effect of $1 \mathrm{~nm}$-cholecystokinin octapeptide on intracellular free $\mathrm{Mg}^{2+}$ concentration in suspensions of magfura-2-loaded pancreatic acinar cells isolated from rats fed a diet containing sunflowerseed oil as the fat source. $(\downarrow)$, The point of addition of the secretagogue.

differing in the degree of unsaturation have been shown to modify insulin binding in rat adipocytes (Field et al. 1989; Clandinin et al. 1991) and the activity of membrane-associated enzymes in liver (Neelands \& Clandinin, 1983), heart (Vajreswari \& Narayanareddy, 1992) and submandibular glands (Alam et al. 1993). Many steps of the stimulus-secretion coupling process in acinar cells are membrane-dependent. Although the present results do not support gross modifications of whole-membrane fluidity, differential enrichment in certain fatty acids may influence the accessibility of the CCK receptor, the interaction with $\mathrm{G}$ proteins or the functionality of such enzymes as phospholipases and protein kinase $\mathrm{C}$ which are known to interact with cell membranes during their activation.

Apart from their structural role, membrane fatty acids participate themselves as mediators in signal transduction. The CCK receptor in rat pancreatic acinar cells (Bourassa et al. 1999) can display two binding (high and low) affinity states and, moreover, CCK occupancy of high and low affinity sites is thought to be related to the initiation of different intracellular events and consequent biological responses (Tsunoda et al. 1996; Gonzalez et al. 1999). The moderately high concentrations of CCK-8 used in the present study probably stimulate low-affinity sites and initiate a route linked to both phospholipase C (PLC) and phospholipase D (Gonzalez et al. 1999). PLC activation involves the hydrolysis of phosphatidylinositol bisphosphate and subsequent production of inositol trisphosphate (IP3), which initiates the $\mathrm{Ca}^{2+}$ signal, and diacylglycerol. The membrane modifications confirmed in the present study after olive-oil and sunflowerseed-oil intake could reasonably involve an alteration in the phosphoinositide turnover and a change in the supply of inositol lipid precursors of IP3. Reduced production of IP3 in acini from rats fed sunflowerseed oil might explain the diminished intracellular free $\mathrm{Ca}^{2+}$ concentration peaks in response to
CCK-8, since it is well known that the initial rise in $\mathrm{Ca}^{2+}$ concentration transients is mainly due to $\mathrm{Ca}^{2+}$ released from IP3-sensitive internal stores. Alternatively, it is tempting to speculate that diacylglycerol, abundantly generated via PLC and phospholipase D (Gonzalez et al. 1999) and possibly with different acyl moieties as a consequence of the observed changes in the membrane, may have resulted in the present study in differential activation of protein kinase $\mathrm{C}$, a crucial modulator of the secretory machinery of acinar cells. This is strongly supported by the finding in guinea-pig epidermis that diacylglycerol with a $18: 2 n-6$ metabolite at the 2-position inhibited protein kinase $\mathrm{C}$ isozymes compared with 1,2-dioleylglycerol (Cho \& Ziboh, 1994). On the other hand, the activation of high-affinity receptor sites by low CCK concentrations is coupled to cytosolic $\mathrm{Ca}^{2+}$-dependent phospholipase $\mathrm{A}_{2}$ (cPLA2) and, to a lower extent, to PLC (Gonzalez et al. 1999). Arachidonic acid $(20: 4 n-6)$ liberated from membrane phospholipids via cPLA2 then slows the $\mathrm{Ca}^{2+}$ wave spreading elicited by CCK (Gonzalez et al. 1999). With the methodology of the present study it was not possible to assess the participation of the cPLA2 cascade but, if there is any, it would occur only after stimulation with $0 \cdot 1 \mathrm{nM}-\mathrm{CCK}-8$. In this case, the significantly higher availability of arachidonic acid in membranes of the sunflowerseed-oil group should be considered.

Concerning intracellular $\mathrm{Mg}^{2+}$ concentrations, the characteristic response to CCK-8 was found (Wisdom et al. 1996). It has been proposed that for optimal generation and maintenance of the $\mathrm{Ca}^{2+}$ signal and enzyme secretion in pancreatic acinar cells, a concomitant decrease in the cellular $\mathrm{Mg}^{2+}$ level is necessary (Wisdom et al. 1996) and, indeed, a fall in intracellular free $\mathrm{Mg}^{2+}$ concentration in both dietary groups was observed after the addition of CCK-8. From a quantitative point of view, however, the changes in intracellular free $\mathrm{Mg}^{2+}$ concentration do not provide an explanation for the different patterns of amylase release and $\mathrm{Ca}^{2+}$ mobilisation in cells isolated from the rats fed different dietary fats.

In conclusion, the results of the present study demonstrate that the type of dietary fat strongly influences the fatty acid composition of rat pancreatic cell membranes and this is associated with a change in the secretory activity and intracellular $\mathrm{Ca}^{2+}$ mobilisation stimulated by CCK-8 in viable pancreatic acini. Lipids are emerging as potent regulators of cell function. At the level of CCK-8evoked transduction pathways in acinar cells, this regulatory action of lipids could potentially involve many steps of the cascade because of the properties they confer on biological membranes or due to their performance as intracellular mediators themselves. Experiments are in progress in order to better characterise the precise mechanisms for the observed effects.

\section{Acknowledgements}

The present study was funded by the Spanish Ministry of Science and Technology (grant no. PB-98 1368). The authors thank the University of Granada for supporting M. A. M. and M. D. Y., recipients of a postdoctoral fellowship and a research contract, respectively. 


\section{References}

Akiyama T, Hirohata Y, Okabayashi Y, Imoto I \& Otsuki M (1998) Supramaximal CCK and CCh concentrations abolish VIP potentiation by inhibiting adenyl cyclase activity. Am $J$ Physiol 275, G1202-G1208.

Alam SQ, Mannino SJ \& Alam BS (1993) Reversal of dietinduced changes in adenylate cyclase activity and fatty acid composition of rat submandibular salivary gland lipids. Arch Oral Biol 38, 387-391.

Ballesta MC, Mañas M, Mataix FJ, Martinez-Victoria E \& Seiquer I (1990) Long-term adaptation of pancreatic response by dogs to dietary fats of different degrees of saturation: olive and sunflower oil. Br J Nutr 64, 487-496.

Begin ME, Ells G, St-Jean P, Vachereau A \& Beaudoin AR (1990) Fatty acid and enzymatic compositional changes in the pancreas of rats fed dietary $n-3$ and $n-6$ polyunsaturated fatty acids. Int $J$ Pancreatol 6, 151-160.

Berlin E, Bhathena SJ, McClure D \& Peters RC (1998) Dietary menhaden and corn oils and the red blood cell membrane lipid composition and fluidity in hyper- and normocholesterolemic miniature swine. J Nutr 128, 1421-1428.

Bourassa J, Laine J, Kruse ML, Gagnon MC, Calvo E \& Morisset J (1999) Ontogeny and species differences in the pancreatic expression and localization of the CCKA receptors. Biochem Biophys Res Commun 260, 820-828.

Bragado MJ, San Roman JI, Gonzalez A, Garcia LJ, Lopez MA \& Calvo JJ (1996) Impairment of intracellular calcium homeostasis in the exocrine pancreas after caerulein-induced acute pancreatitis in the rat. Clin Sci 91, 365-369.

Cho Y \& Ziboh VA (1994) Expression of protein kinase C isozymes in guinea pig epidermis: selective inhibition of PKC-beta activity by 13-hydroxyoctadecadienoic acid-containing diacylglycerol. J Lipid Res 35, 913-921.

Clandinin MT, Cheema S, Field CJ, Garg ML, Venkatraman J \& Clandinin TR (1991) Dietary fat: exogenous determination of membrane structure and cell function. FASEB J 5, 2761-2769.

Field CJ, Toyomizu M \& Clandinin MT (1989) Relationship between dietary fat, adipocyte membrane composition and insulin binding in the rat. J Nutr 119, 1483-1489.

Giron MD, Criado MD, Lara A \& Suarez MD (1995) Changes in the fatty acid pattern of plasma fractions of rats fed coconut, olive or sunflower oil. Rev Esp Fisiol 51, 65-69.

Giron MD, Lara A \& Suarez MD (1996) Short-term effects of dietary fats on the lipid composition and desaturase activities of rat liver microsomes. Biochem Mol Biol Int 40, 843-851.

Gonzalez A, Schmid A, Sternfeld L, Krause E, Salido GM \& Schulz I (1999) Cholecystokinin-evoked $\mathrm{Ca}^{2+}$ waves in isolated mouse pancreatic acinar cells are modulated by activation of cytosolic phospholipase $\mathrm{A}_{2}$, phospholipase $\mathrm{D}$, and protein kinase C. Biochem Biophys Res Commun 261, 726-733.

Grynkiewicz G, Poenie M \& Tsien RY (1985) A new generation of $\mathrm{Ca}^{2+}$ indicators with greatly improved fluorescence properties. J Biol Chem 260, 3440-3450.

Jensen RT, Lemp GF \& Gardner JD (1982) Interactions of $\mathrm{COOH}$-terminal fragments of cholecystokinin with receptors on dispersed acini from guinea pig pancreas. $J$ Biol Chem 257, 5554-5559.

Lajas AI, Pozo MJ, Salido GM \& Pariente JA (1998) Effect of basic fibroblast growth factor on cholecystokinin-induced amylase release and intracellular calcium increase in male rat pancreatic acinar cells. Biochem Pharmacol 55, 903-908.

Lepage G \& Roy CC (1986) Direct transesterification of all classes of lipids in a one-step reaction. J Lipid Res 27, 114-119.

Meldolesi J, Jamieson JD \& Palade GE (1971) Composition of cellular membranes in the pancreas of the guinea pig. $J$ Cell Biol 49, 109-129.
Neelands PJ \& Clandinin MT (1983) Diet fat influences liver plasma-membrane lipid composition and glucagon-stimulated adenylate cyclase activity. Biochem J 212, 573-583.

Peikin SR, Rottman AJ, Batzri S \& Gardner JD (1978) Kinetics of amylase release by dispersed acini prepared from guinea pig pancreas. Am J Physiol 235, E743-E749.

Quiles JL, Huertas JR, Mañas M, Battino M \& Mataix J (1999) Physical exercise affects the lipid profile of mitochondrial membranes in rats fed virgin olive oil or sunflower oil. $\mathrm{Br} J$ Nutr 81, 21-24.

Quiles JL, Huertas JR, Mañas M, Ochoa JJ, Battino M \& Mataix J (2001) Dietary fat type and regular exercise affect mitochondrial composition and function depending on specific tissue in the rat. J Bioenerg Biomembr 33, 127-134.

Reeves PG, Nielsen FH \& Fahey GC Jr (1993) AIN-93 purified diets for laboratory rodents: final report of the American Institute of Nutrition ad hoc writing committee on the reformulation of the AIN-76A rodent diet. J Nutr 123, 1939-1951.

Ricketts J \& Brannon PM (1994) Amount and type of dietary fat regulate pancreatic lipase gene expression in rats. $J$ Nutr $\mathbf{1 2 4}$, $1166-1171$.

Sabb JE, Godfrey PM \& Brannon PM (1986) Adaptive response of rat pancreatic lipase to dietary fat: effects of amount and type of fat. J Nutr 116, 892-899.

Serrano P, Yago MD, Mañas M, Calpena R, Mataix J \& MartinezVictoria E (1997) Influence of type of dietary fat (olive and sunflower oil) upon gastric acid secretion and release of gastrin, somatostatin and peptide YY in man. Dig Dis Sci 42, 626-633.

Soriguer FJ, Tinahones FJ, Monzon A, et al. (2000) Varying incorporation of fatty acids into phospholipids from muscle, adipose and pancreatic exocrine tissues and thymocytes in adult rats fed with diets rich in different fatty acids. Eur J Epidemiol 16, 585-594.

Suarez A, Faus MJ \& Gil A (1996a) Dietary long-chain polyunsaturated fatty acids modify heart, kidney, and lung fatty acid composition in weanling rats. Lipids 31, 345-348.

Suarez A, Ramirez MCD, Faus MJ \& Gil A (1996b) Dietary longchain polyunsaturated fatty acids influence tissue fatty acid composition in rats at weaning. $J$ Nutr 126, 887-897.

Thomson AB, Keelan M, Cheng T \& Clandinin MT (1993) Delayed effects of early nutrition with cholesterol plus saturated or polyunsaturated fatty acids on intestinal morphology and transport function in the rat. Biochim Biophys Acta 1170, 80-91.

Tsunoda Y, Yoshida H \& Owyang C (1996) Structural requirements of CCK analogues to differentiate second messengers and pancreatic secretion. Am J Physiol 271, G8-G19.

Vajreswari A \& Narayanareddy K (1992) Effect of dietary fats on some membrane-bound enzyme activities, membrane lipid composition and fatty acid profiles of rat heart sarcolemma. Lipids 27, 339-343.

Wang H, Dudley AW Jr, Dupont J, Reeds PJ, Hachey DL \& Dudley MA (1996) The duration of medium-chain triglyceride feeding determines brush border membrane lipid composition and hydrolase activity in newly weaned rats. J Nutr 126, 1455-1462.

Wisdom DM, Salido GM, Baldwin LM \& Singh J (1996) The role of magnesium in regulating CCK-8-evoked secretory responses in the exocrine rat pancreas. Mol Cell Biochem 154, 123-132.

Yago MD, Gonzalez MV, Martinez-Victoria E, et al. (1997a) Pancreatic enzyme secretion in response to test meals differing in the quality of dietary fat (olive oil and sunflowerseed oils) in human subjects. Br J Nutr 78, 27-39.

Yago MD, Martinez-Victoria E, Mañas M, Martinez MA \& Mataix J (1997b) Plasma peptide YY and pancreatic polypeptide in dogs after long-term adaptation to dietary fats of different degrees of saturation: olive and sunflower oil. J Nutr Biochem 8, 502-507. 